\section{Untranslatierte Region (UTR)}

\section{J. Arnemann}

Abteilung Molekulargenetik, Labor Dr. Wisplinghoff, Köln, Deutschland

$\operatorname{Synonym(e)}$ untranslatiertes $5^{`}$ oder $3^{`}$-Ende

Englischer Begriff untranslated region (UTR)

Definition Untranslatierte Region definiert die im 5'- und 3'-Bereich des offenen Leserahmens lokalisierten Abschnitte der mRNA.

Beschreibung Die reife, gespleißte mRNA enthält neben dem für eine Aminosäureabfolge kodierenden offenen Leserahmen (ORF) flankierend im 5'- und im 3'-Bereich Abschnitte, die nicht in eine Aminosäuresequenz translatiert werden und daher als $5^{6}$ - bzw. $3^{\prime}$-untranslatierter (5'-UTR bzw. 3'-UTR) Bereich bezeichnet werden.
Der 5'-UTR-Bereich beginnt mit dem eigentlichen Transkriptionsstartpunkt (Position +1 ) und erstreckt sich bis unmittelbar vor den Translationsstartpunkt (AUG-Codon) und beinhaltet für die Translation relevante regulatorische Abschnitte und vor allem im Übergang zur translatierten Sequenz die Startcodonerkennungssequenz, die meist aus der Abfolge $\mathrm{GCC}(\mathrm{A} / \mathrm{G}) \mathrm{CC} \boldsymbol{A} \boldsymbol{U} \boldsymbol{G G}$ besteht und von der 40S-Untereinheit der Ribosomen als solche erkannt wird.

Der 3'-UTR-Bereich erstreckt sich vom eigentlichen Stoppcodon der Translation bis zum Beginn der Polyadenylierung. In diesem Bereich finden sich ebenfalls regulatorische Abschnitte für die Translation sowie auch die Polyadenylierungssequenz, die das Ende der mRNA und den Beginn der Polyadenylierung ca. 15-30 bp stromabwärts definiert.

\section{Literatur}

Hinnebush AG et al (2016) Translational control by 5'-untranslated regions of eukaryotic mRNAs. Science 352:1413-1416

Schwerk J, Savan R (2015) Translating the untranslated region. J Immunol 195:2963-2971 